\title{
-Original-
}

\section{Evaluation of Parameters of Serially Monitored F-wave in Acute Cervical Spinal Cord Injury}

\author{
Yong Kim, Takafumi Aoki and Hiromoto Ito \\ Department of Restorative Medicine of Neuro-musculoskeretal System, Orthopaedic Surgery, \\ Graduate School of Medicine, Nippon Medical School
}

\begin{abstract}
Objective: In this study, we aimed to determine how physicians can evaluate the severity of acute traumatic spinal cord injury (SCI) and predict the prognosis of this injury using the relationships of changes in clinical features and electrophysiological examination results.

Materials and Methods: Serial recordings of F-waves were performed on 20 consecutive cervical SCI patients. In 12 of the patients, changes in several parameters of F-waves which were elicited by median and ulnar nerve stimulations were examined by analyzing their relationships to clinical symptoms.

Results: The maximum amplitude of the F-waves (F-max) elicited by median nerve stimulation was found to be the most reliable (statistically significant) parameter for distinguishing clinically improved patients from nonimproved patients for the prognosis in the early stages after trauma. Other parameters, including the incidence of $\mathrm{F}$-waves and the mean F-wave amplitude both of which were elicited by median nerve stimulation, were somewhat helpful for predicting the prognosis. These parameters of F-waves evoked by ulnar nerve stimulation could be useful for several weeks post-trauma.
\end{abstract}

(J Nippon Med Sch 2007; 74: 106-113)

Key words: cervical spinal cord injury, F-wave, prognosis, functional recovery

\section{Introduction}

Spinal cord injury (SCI) is one of the most serious traumas in the clinical field. After a traumatic cervical spinal cord injury, recovery is variable because of varying lesion severity, which depends on the damage of spinal tracts. Three phases after SCI have been defined by clinical means: spinal shock phase, transition phase (early phase recovery), and spastic state phase (late phase recovery). However, the onset of transition and spastic state phases are difficult to determine because the transition to a clearly defined spasticity is smooth. There have been a few attempts to evaluate the severity of SCI and to define the prognosis from clinical aspects ${ }^{12}$. However, magnetic resonance imaging (MRI) of the injured spinal cord is usually difficult to perform consecutively and repeatedly ${ }^{3-5}$. Examinations of the voluntarily contracted

Correspondence to Yong Kim, Department of Restorative Medicine of Neuro-musculoskeretal System, Orthopaedic Surgery, Graduate School of Medicine, Nippon Medical School, 1-1-5 Sendagi Bunkyo-ku, Tokyo 113-8603, Japan E-mail: ichijo@nms.ac.jp Journal Website (http://www.nms.ac.jp/jnms/) 
F-wave in Acute Cervical Spinal Cord Injury

Table 1 Patients profiles

\begin{tabular}{|c|c|c|c|c|c|c|c|}
\hline Patient & Age & Sex & Injury & $\begin{array}{c}\text { Injured } \\
\text { Level }\end{array}$ & $\begin{array}{l}\text { Initial } \\
\text { ASIA* }\end{array}$ & $\begin{array}{l}\text { Final } \\
\text { ASIA* }\end{array}$ & $\begin{array}{l}\text { Spinal } \\
\text { Shock }\end{array}$ \\
\hline \multicolumn{8}{|c|}{ improved } \\
\hline 1 & 54 & $\mathrm{~F}$ & C5/6 dislocation & $\mathrm{C} 6$ & $\mathrm{D}$ & $\mathrm{E}$ & No \\
\hline 2 & 56 & $\mathrm{~F}$ & OPLL & $\mathrm{C} 6$ & $\mathrm{C}$ & $\mathrm{D}$ & No \\
\hline 3 & 66 & $\mathrm{~F}$ & C4 compression $\mathrm{fx}$. & $\mathrm{C} 6$ & $\mathrm{~A}$ & $\mathrm{D}$ & No \\
\hline 4 & 58 & M & CSCS & $\mathrm{C} 6$ & $\mathrm{C}$ & $\mathrm{D}$ & No \\
\hline 5 & 71 & $\mathrm{M}$ & CSCS & $\mathrm{C} 6$ & $\mathrm{C}$ & $\mathrm{D}$ & No \\
\hline 6 & 66 & $\mathrm{M}$ & $\mathrm{C} 3 / 4$ dislocation & $\mathrm{C} 5$ & B & $\mathrm{E}$ & No \\
\hline \multicolumn{8}{|c|}{ nonimproved } \\
\hline 7 & 76 & $\mathrm{M}$ & OPLL & $\mathrm{C} 6$ & A & $\mathrm{A}$ & No \\
\hline 8 & 63 & $\mathrm{M}$ & C5/6 dislocation & $\mathrm{C} 5$ & A & $\mathrm{A}$ & Yes \\
\hline 9 & 65 & $\mathrm{M}$ & $\mathrm{C} 4 / 5$ dislocation & $\mathrm{C} 6$ & A & $\mathrm{A}$ & Yes \\
\hline 10 & 23 & $\mathrm{M}$ & C6 compression $\mathrm{fx}$. & $\mathrm{C} 7$ & $\mathrm{~A}$ & $\mathrm{~A}$ & Yes \\
\hline 11 & 39 & $\mathrm{M}$ & C5, 6 compression $\mathrm{fx}$. & $\mathrm{C} 7$ & $\mathrm{~A}$ & $\mathrm{~A}$ & No \\
\hline 12 & 57 & $\mathrm{M}$ & $\mathrm{C} 4 / 5$ dislocation & $\mathrm{C} 6$ & A & $\mathrm{A}$ & Yes \\
\hline
\end{tabular}

*ASIA=ASIA impairment scale

OPLL: ossification of posterior longitudinal ligament of cervical spine

CSCS: cervical spinal canal stenosis

Clinical profiles of patients involved in this study. In the ASIA impairment scale columns, grade "A"

indicates the worst condition, i.e., complete paralysis, and grade "E" indicates no signs of paralysis.

discharges of peripheral muscles provide no help in investigating the severity of SCI in the early stages after the trauma ${ }^{6.7}$. Once motor loss of upper and lower limbs occurs in a patient, recovery of function is the most important concern for the patient. In other words, evaluating the extent of damage to the spinal cord as quickly as possible is the most important event for predicting the prognosis of the patient. In this study, we investigated changes in clinical symptoms and monitored $\mathrm{F}$-waves over time in 20 cases of acute cervical SCI. Clarification of the changes in various parameters of $\mathrm{F}$-waves and their relationships to clinical symptoms is the aim of this study.

\section{Materials and Methods}

\section{General Procedures and Patients}

Twenty acute cervical SCI patients who were admitted to Emergency and Critical Care Center of Nippon Medical School Hospital were employed in this study. All the patients gave informed consent before undergoing the clinical and electrophysiological examinations. These examinations were performed in parallel as early as possible after the injury, and daily for 1 week and weekly for 5 weeks. This schedule was kept flexible in accordance with the necessities of intensive care or the patients' mental condition. Of the 20 original patients, 8 were excluded because of a short followup duration of less than 3 weeks, coexisting traumatic brain injury, or a history of nervous system disease and senile dementia. Of the remaining 12 patients, 9 were male and 3 were female and their ages ranged from 23 to 76 years. The clinical level of SCI was defined by radiographic examinations (i.e., X-ray, CT and MRI) and the severity of SCI was determined on the basis of the protocol of the American Spinal Cord Injury Association (ASIA). An overview of the patients' clinical data is shown in Table $\mathbf{1}$.

The patients were divided into two groups, namely, the improved group and the nonimproved group, using the ASIA impairment scale. All clinical examinations were carried out under identical conditions by the same person according to the protocol.

\section{Electrophysiological Methods}

Muscle evoked potentials of M-waves and F-waves (Fig. 1) were recorded using Neuropack 8, an electromyograph machine provided by Nihon Koden Inc., Japan. Single rectangular wave stimuli of 0.2 msec duration at a frequency of $1 \mathrm{~Hz}$ were applied 


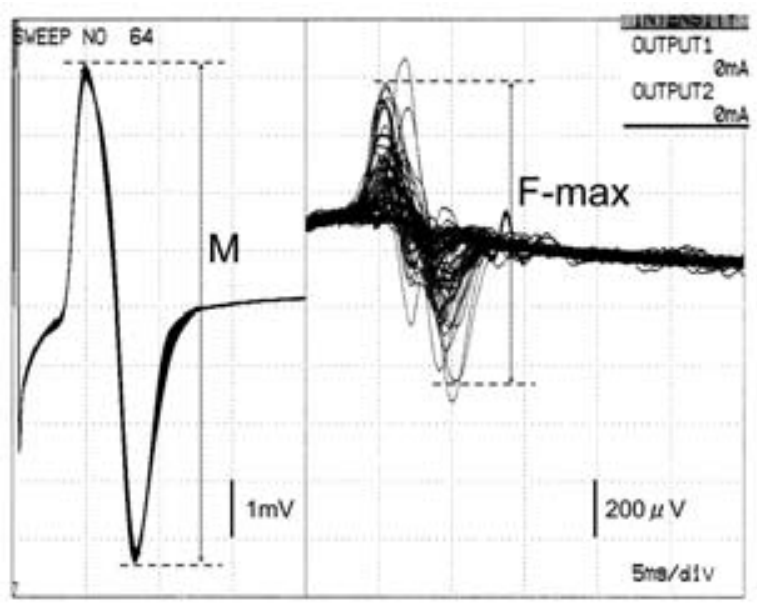

Fig. 1 Sixty four times superimposed M-waves and $\mathrm{F}$-waves are shown in this figure. Mwaves are stable and their amplitudes are almost the same $(\mathrm{M})$; F-waves are rather variable in each stimulus. Maximum amplitude of F-waves (F-max), mean amplitude and incidence of $\mathrm{F}$-waves were evaluated in this study.

64 times consecutively with supramaximal stimulus intensity to the bilateral median and ulnar nerves distally at the wrist. Motor-nerve-evoked discharges were recorded using bipolar surface electrodes placed in the muscle belly-tendon maneuver. The targeted muscles were the abductor pollicis brevis (APB) for median nerve stimulation and the abductor digiti minimi (ADM) for ulnar nerve stimulation. The excitabilities of the F-waves measured were expressed as maximum amplitude (F-max), mean amplitude (F-mean), and the frequency of F-wave occurrence (F-occur: the number of measurable $\mathrm{F}$-waves divided by the number of stimuli). The maximum amplitude ratio of the F-waves to the M-wave $(\mathrm{F}$-max $/ \mathrm{M})$, the mean amplitude ratio of the $\mathrm{F}$-waves to the M-wave ( $\mathrm{F}$ mean/M) and M-wave amplitude were also evaluated. Unpaired Student's t-test was used for statistical analysis for comparisons between the improved group and the nonimproved group in terms of the measurable F-wave and M-wave parameters described above. Differences with a $p$ value less than 0.05 were considered significant. The relationship between clinical and electrophysiological results was assessed.

\section{Results}

Twelve of the 20 patients were studied over 5 weeks successively. Six of these 12 patients showed some recovery of motor function (i.e., incomplete paralysis) and were classified into the improved group. Six remained clinically holding complete loss of sensory and motor functions (grade A of ASIA impairment scale) and were classified into the nonimproved group. Of the 6 patients of the nonimproved group, 4 showed clinical signs of spinal shock during the first examination (i.e., complete paralysis, areflexia, loss of sensation, and muscle hypotonia caudal to the injured level). However, all of the 4 patients had the bulbocavernosus reflex during the first examination. Tendon reflexes reappeared over 2 to 3 weeks after SCI. F-waves could be elicited in 11 patients during the initial examination irrespective of group even though the 4 patients were in spinal shock.

Figure 2 shows the changes in F-max (elicited by median nerve stimulation) in patients of both groups with the post-traumatic time course. Serial studies of F-max indicated that the maximum amplitude of the F-waves of the nonimproved group was significantly lower than that of the improved group. There were statistically significant differences on day 5 , and weeks 1, 3 and 4 between the two groups. As for Foccur, the production of F-wave frequency was suppressed more in the nonimproved group than in the improved group. Statistically significant differences were recognized on day 5 , and weeks 1 and 5 (Fig. 3) . The values of F-mean were realized to have the same tendency of regression during the time (Fig. 4) . F-max/M and F-mean/M had a few significant suppression periods in the nonimproved group compared with the F-max/M and F-mean/M of the improved group. All of these F-wave parameters evaluated for the tests of ulnar nerve stimulation had a different manner. It means that time points with statistically significant difference for the tests of ulnar nerve were fairly different from those for the tests of median nerve. Statistically significant differences were identified only at weeks 4 and 5 for most of the parameters 


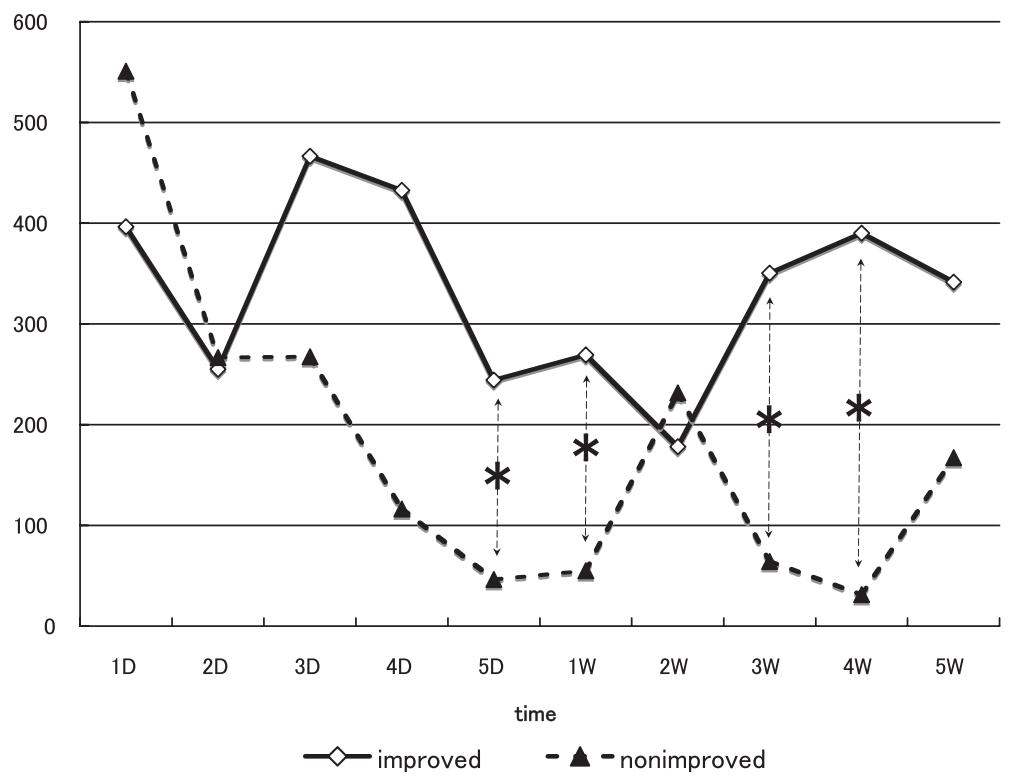

Fig. 2 Changes in maximum amplitude of F-waves during follow-up period. The solid line represents the improved group, and the dotted line represents the nonimproved group. Statistically significant differences were realized between both groups on day 5 , and weeks 1,3 and 4 post-trauma $\left({ }^{*}\right)$.

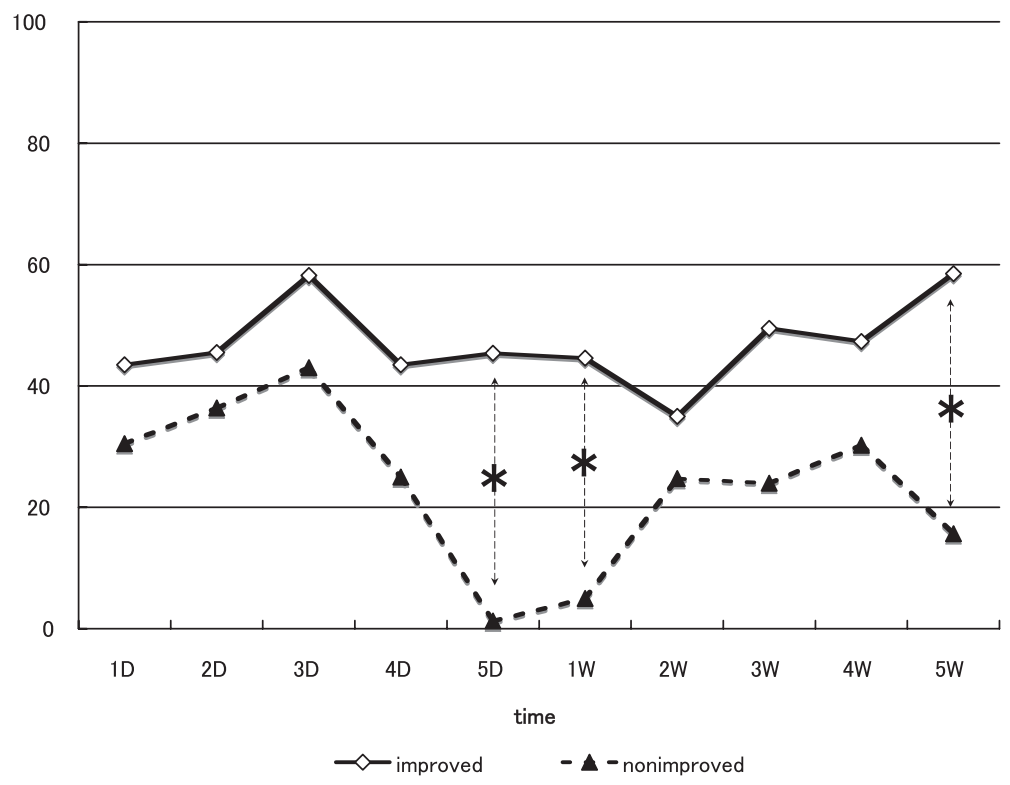

Fig. 3 Changes in frequency of occurrence of F-waves during follow-up period. The solid line, improved group; dotted line, nonimproved group. Statistically significant differences were realized between both groups on day 5 , and weeks 1 and 5 post-trauma (*).

evaluated by ulnar nerve stimulation. Table 2 shows the times (days and weeks) in which each parameter showed statistically significant differences between the improved and the nonimproved groups. Among the significant periods, day 5 seemed to be the most significant day because of its suggestive time point for predicting the prognosis with significance between the two groups.

The initial values of each parameter were compared with those within the follow-up period. No statistically significant difference was recognized for any parameters in the improved group. On the other 


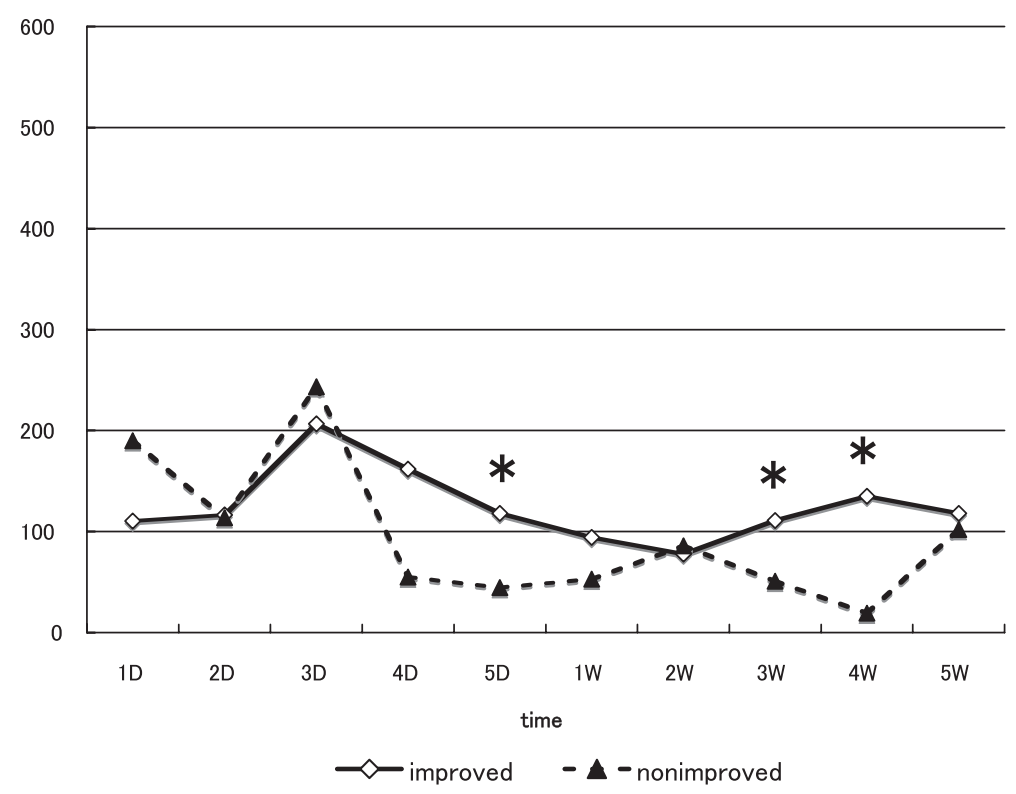

Fig. 4 Changes in mean amplitude of F-waves during follow-up period. The solid line, improved group: dotted line, nonimproved group. Statistically significant differences were realized between both groups on day 5 , and weeks 3 and 4 post-trauma (*).

Table 2 Comparison between improved group and nonimproved group in days and weeks

\begin{tabular}{|c|c|c|c|c|c|c|c|c|c|c|}
\hline & $1 \mathrm{D}$ & $2 \mathrm{D}$ & $3 \mathrm{D}$ & $4 \mathrm{D}$ & $5 \mathrm{D}$ & $1 \mathrm{~W}$ & $2 \mathrm{~W}$ & $3 W$ & $4 \mathrm{~W}$ & $5 \mathrm{~W}$ \\
\hline $\begin{array}{l}\text { F-max (m) } \\
\text { F-max }(\mathrm{u})\end{array}$ & & & & & 0 & 0 & & 0 & 0 & 0 \\
\hline $\begin{array}{l}\text { F-occur (m) } \\
\text { F-occur (u) }\end{array}$ & & & & & 0 & 0 & & 0 & & 0 \\
\hline $\begin{array}{l}\text { F-mean }(\mathrm{m}) \\
\text { F-mean }(\mathrm{u})\end{array}$ & & & & & 0 & & & 0 & 0 & 0 \\
\hline $\begin{array}{l}\text { F-max/M (m) } \\
\text { F-max/M (u) }\end{array}$ & & & & & 0 & & & & 0 & 0 \\
\hline $\begin{array}{l}\text { F-mean/M (m) } \\
\text { F-mean/M (u) }\end{array}$ & & & & & & & & & 0 & 0 \\
\hline $\begin{array}{l}\mathrm{M}(\mathrm{m}) \\
\mathrm{M}(\mathrm{u})\end{array}$ & & & 0 & & & & & 0 & & \\
\hline
\end{tabular}

Time points of days and weeks post-trauma in which statistically significant differences were realized between improved group and nonimproved group for each electrophysiological parameter (O). Parameters given by median nerve stimulation are identified with $(\mathrm{m})$, and those given by ulnar nerve stimulation are identified with $(\mathrm{u})$.

hand, a statistically significant difference was evident for the F-max elicited by median nerve stimulation 4 days post-trauma in the nonimproved group (Fig. 5a, b and Table 3). M-wave amplitude gradually decreased and became significantly different from the initial amplitude after 1 week; however, no significant difference was seen between the improved and nonimproved groups (Fig. 6) .

\section{Discussion}

F-waves are very fine muscle evoked potentials originating from antidromically activated anterior horn cells and project the excitability of an $\alpha$ motoneuron pool in a particular spinal segment $t^{8}$. Note that F-waves represent only a very small 
a

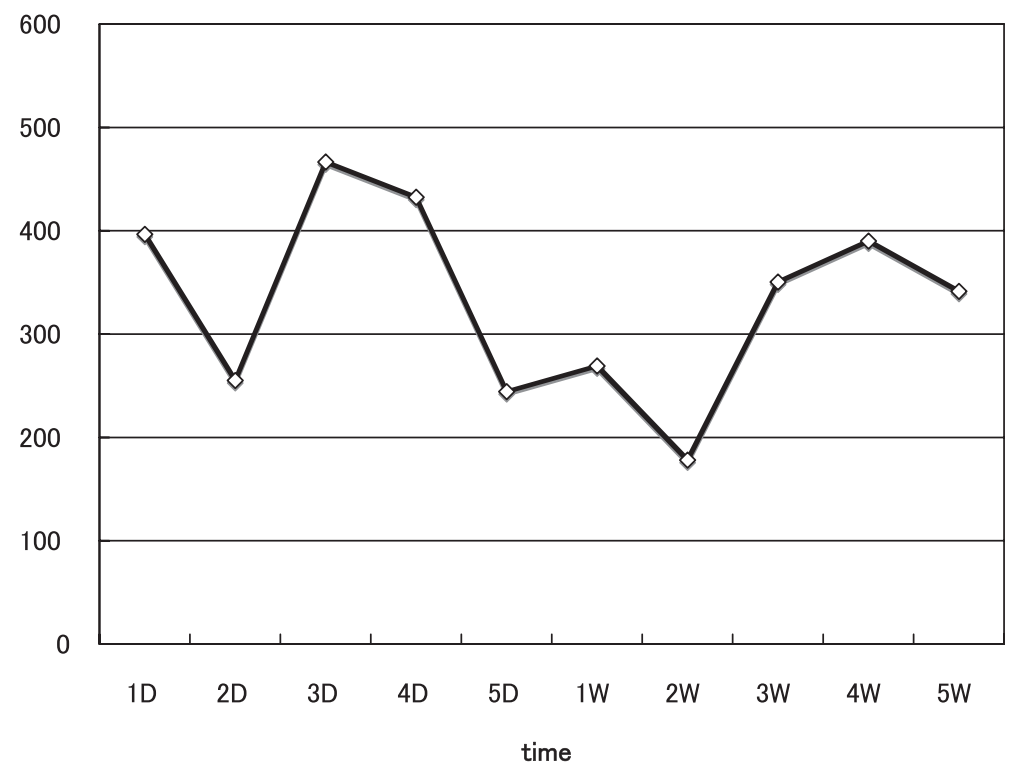

b

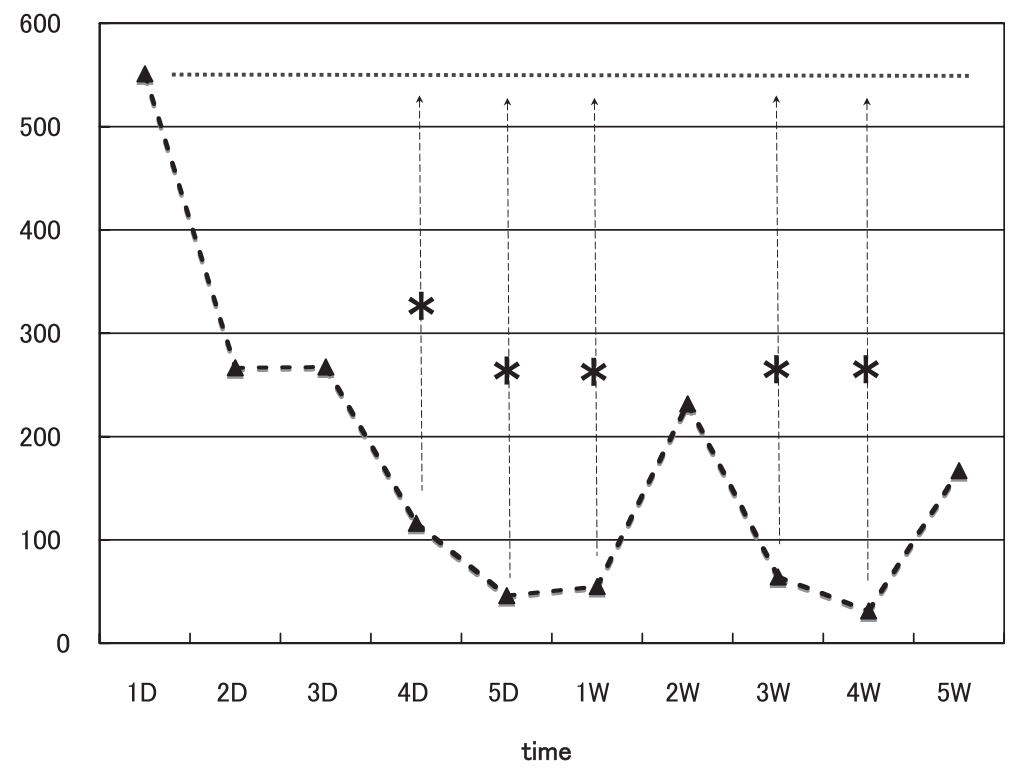

Fig. 5 a: No statistically significant difference was found for changes in F-max compared with the initial F-max in the improved group. b: Statistically significant difference was shown at the time point of days 4 and 5 and weeks 1,3 and 4 post-trauma compared the initial value in the nonimproved group.

population of activities of backfired motoneurons? However, this does not mean that F-waves represent a specific group of motoneurons; it means that F-waves can be generated by motoneurons of all sizes. F-waves are considered to reflect the altered excitability of the motoneuron pool in patients with conditions such as upper motoneuron lesions, limb spasticity due to cerebrovascular disorders or SCI, and cervical spondylotic myelopathy ${ }^{10-12}$. F-wave amplitude, duration and incidence increase in patients with spasticity, corresponding to an exaggerated reflex excitability ${ }^{13}$, whereas F-wave latencies are unaffected ${ }^{14.15}$. Evaluating the frequency of $\mathrm{F}$-wave production and M-wave amplitude for patients with cervical SCI can be used to assess the severity and extent of damage 
Y. Kim, et al

Table 3 Comparison between initial value and later values in statistical significance

\begin{tabular}{|c|c|c|c|c|c|c|c|c|c|c|}
\hline & $1 \mathrm{D}$ & $2 \mathrm{D}$ & $3 \mathrm{D}$ & $4 \mathrm{D}$ & $5 \mathrm{D}$ & $1 \mathrm{~W}$ & $2 \mathrm{~W}$ & $3 \mathrm{~W}$ & $4 \mathrm{~W}$ & $5 \mathrm{~W}$ \\
\hline $\begin{array}{l}\text { F-max (m) imp. } \\
\text { not-imp. } \\
\text { F-max (u) imp. } \\
\text { not-imp. }\end{array}$ & & & & 0 & 0 & 0 & & 0 & 0 & \\
\hline $\begin{array}{r}\text { F-occur (m) imp. } \\
\text { not-imp. } \\
\text { F-occur (u) imp. } \\
\text { not-imp. }\end{array}$ & & & & & 0 & 0 & & 0 & & \\
\hline $\begin{array}{l}\text { F-mean (m) imp. } \\
\text { not-imp. } \\
\text { F-mean (u) imp. } \\
\text { not-imp. }\end{array}$ & & & & & 0 & & & & 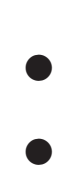 & 0 \\
\hline
\end{tabular}

Time points of days and weeks post-trauma in which statistically significant differences were realized between initial value of each parameter and values that varied during the time course (). The changes in the values of the improved group are identified with "imp.," and those of the nonimproved group are identified with "nonimp."

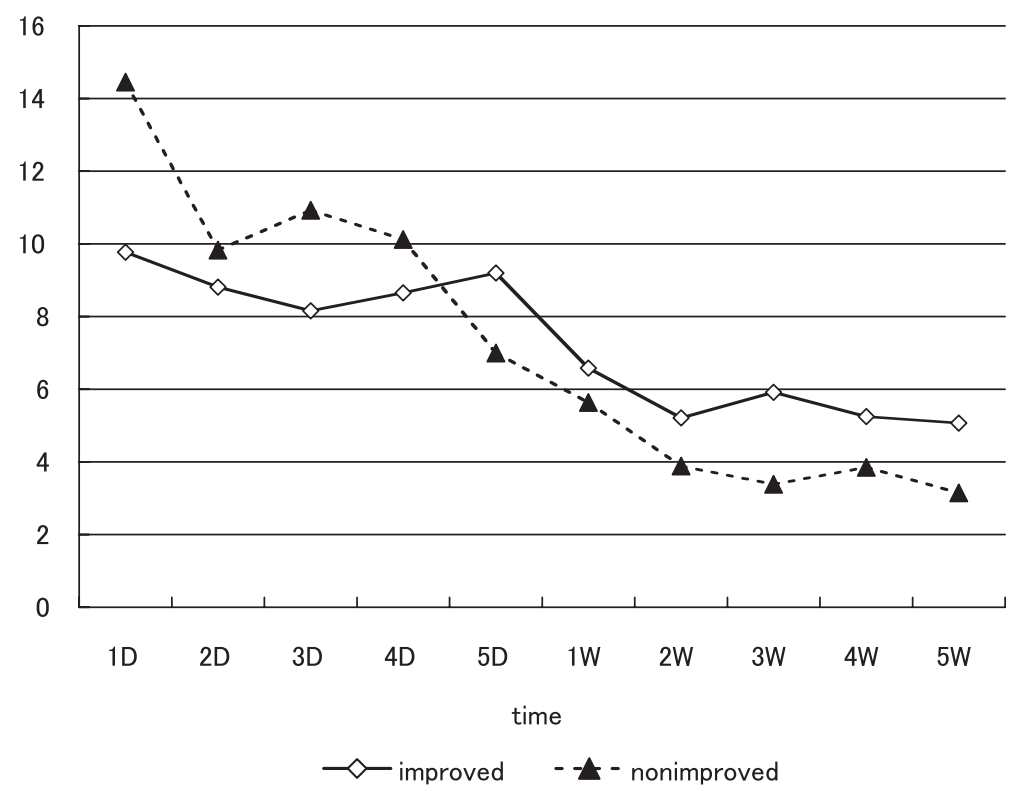

Fig. 6 Both lines represent changes in M-wave amplitudes. In line with the gradually decreasing value in both groups, however, no statistically significant difference between both groups was found.

to the motoneuron pool ${ }^{16,17}$. Unfortunately, there are few reports on the relationships between electrophysiological results and the clinical recovery from motor or sensory dysfunction ${ }^{18,19}$. In this study, we analyzed F-waves elicited by peripheral nerve stimulation, which originates from a segmentally damaged motoneuron pool. Systematic serial examinations were performed in the earliest stage of SCI, and the results were analyzed to determine the clinical and electrophysiological relationships.

F-waves were recorded from almost all the patients (all but one) regardless of the existence of spinal shock during the first examination. A previous study showed that F-waves were absent during spinal shock. Four patients were clinically determined to have spinal shock, and all of them showed the bulbocavernosus reflex during the initial examinations in this study. This may have resulted in the patients' very quick recovery from true spinal shock or the difference in the level of the injured spinal cord.

The results showed that the most reliable 
parameter for distinguishing the improved group from the nonimproved group within the early stage of SCI was the median-nerve-evoked F-max. It had the most time points with statistically significant differences throughout the entire examination period. Median-nerve-elicited F-occur and F-mean were suggested to be relatively reliable, because they did not have as many time points with statistically significant differences as F-max. In terms of ulnar-nerve-evoked F-wave parameters, Fmax, F-occur and F-mean were valuable only for approximately 4 weeks or later post-trauma. It may be suggested there was some degree of difference in the excitability of the motoneuron pools supplying the median (C5. 6. 7. 8, Th1) and ulnar (C7, 8, Th1) nerves. In this study, more than $80 \%$ of the patients were injured at C5 and C6 spinal levels, which is related to the median nerve projection but not to the ulnar nerve. On day 5, F-wave production results from median nerve stimulation showed the first statistically significant difference between the improved group and the nonimproved group during the examination period. The reason for these results has not yet been identified; however, once motoneurons are injured, they may affect the activities of whole motoneurons through interneurons, which finally diminishes the excitability of the motoneuron pool. We conclude that in the earliest stages of cervical SCI, it is recommended that the median-nerve-stimulated $\mathrm{F}$ waves be evaluated to predict the prognosis of the patients. F-max evaluation followed by daily F-occur and F-mean analysis post-trauma will help to assess the prognosis for functional recovery.

\section{References}

1. Katoh S, el Masry WS: Motor recovery of patients presenting with motor paralysis and sensory sparing following cervical spinal cord injuryies. Paraplegia 1995; 33: 506-509.

2. Dvorak MF, Fisher CG, Hoekema J, et al: Factors predicting motor recovery and functional outcome after traumatic central cord syndrome: a long-term follow-up. Spine 2005; 30: 2303-2311.

3. Boldin C, Raith J, Fankhauser F, Haunschmid C, Schwantzer G, Schweighofer F: Predicting neurologic recovery in cervical spinal cord injury with postoperative MR Imaging. Spine 2006; 31: 554559.

4. Ishida Y, Tominaga T: Predictors of neurologic recovery in acute central cervical cord injury with only upper extremity impairment. Spine 2002; 27: $1652-1658$

5. Ohta K, Fujimura Y, Nakamura M, Watanabe M, Yato Y: Experimental study on MRI evaluation of the course of cervical spinal cord injury. Spinal Cord 1999; 37: 580-584

6. Calancie B, Molano MR, Broton JG: EMG for assessing the recovery of vulntaru movement after acute spinal cord injury in man. Clin Neurophysiol 2004; 115: 1748-1759.

7. Alexeeva N, Broton JG, Suys S, Calancie B: Central cord syndrome of cervical spinal cord injury: widespread changes in muscle recruitment studied by voluntary contractions and transcranial magnetic stimulation. Exp Neurol 1997; 148: 399-406.

8. Kimura J, Yanagisawa H, Yamada T, Mitsudome A, Sasaki H, Kimura A: Is the $F$ wave elicited in a select group of motoneurons? Muscle Nerve 1984; 7 : 392-399.

9. Dengler R, Kossev A, Wohlfahrt K, Schubert M, Elek J, Wolf W: F waves and motor unit size. Muscle Nerve 1992; 15: 1138-1142.

10. Fierro B, Raimondo D, Modica A: Analysis of F response in upper motoneurone lesions. Acta Neurol Scand 1990; 82: 329-334.

11. Milanov I: Examination of the segmental pathophysiological mechanisms of spasticity. Electromyogr clin Neurophysiol 1994; 34: 73-79.

12. Fisher MA: F response analysis of motor disorders of central origin. J Neurol Sci 1983; 62: 13-22.

13. Schiller HH, Stalberg E: F responses studied with single fiber EMG in normal subjects and spastic patients. J Neurol Neurosurg Psychiatry 1978; 41: $45-53$.

14. Bischoff C, Schoenle PW, Conrad B: Increased Fwave duration in patients with spasticity. Electromyogr clin Neurophysiol 1992; 2: 449-453.

15. Eisen A, Odusote K: Amplitude of the $\mathrm{F}$ wave: a potential means of documenting spasticity. Neurology 1979; 29: 1306-1309.

16. O'Hare JM, Abbort GH: Electromyographic evidence of lower motor neuron injury in cervical spinal cord injury. Proc Annu Clin Spinal Cord Inj Conf 1967; 16: $25-27$.

17. Curt A, Dietz V: Neurographic assessment of intramedullar motoneurone lesions in cervical spinal cord injury: consequences of hand function. Spinal Cord 1996; 34: 326-332.

18. Leis AA, Kronenberg MF, Stetkarova I, Paske WC, Stokic DS: spinal motoneuron excitability after acute spinal cord injury in humans. Neurology 1996; 47: 231-237.

19. Curt A, Keck ME, Dietz V: Clinical value of F-wave recordings in traumatic cervical spinal cord injury. Electroencephalography and clinical Neurophysiology 1997; 105: 189-193.

(Received, December 12, 2006)

(Accepted, December 29, 2006) 